\title{
Comparison of 2002 AECG and 2016 ACR/ EULAR classification criteria and added value of salivary gland ultrasonography in a patient cohort with suspected primary Sjögren's syndrome
}

Maëlle Le Goff', Divi Cornec ${ }^{1,2^{*}}$, Sandrine Jousse-Joulin ${ }^{1,2}$, Dewi Guellec ${ }^{1}$, Sebastian Costa ${ }^{2,3}$, Thierry Marhadour ${ }^{1}$, Rozenn Le Berre ${ }^{4}$, Steeve Genestet ${ }^{5}$, Béatrice Cochener ${ }^{6}$, Sylvie Boisrame-Gastrin ${ }^{7}$, Yves Renaudineau ${ }^{2,8}$, Jacques-Olivier Pers ${ }^{2,7}$, Alain Saraux ${ }^{1,2}$ and Valérie Devauchelle-Pensec ${ }^{1,2}$

\begin{abstract}
Background: The objective was to evaluate concordance between 2002 American-European Consensus Group (AECG) and 2016 American College of Rheumatology (ACR)/European League Against Rheumatism (EULAR) classification criteria for primary Sjögren's syndrome (pSS) and to assess how salivary gland ultrasonography (SGUS) might improve the classification of patients.
\end{abstract}

Methods: Patients with suspected pSS underwent a standardised evaluation, including SGUS, at inclusion into the single-centre Brittany DIApSS cohort. Agreement between the two criteria sets was assessed using Cohen's k coefficient. Characteristics of discordantly categorised patients were detailed.

Results: We prospectively included 290 patients between 2006 and 2016, among whom 125 (43\%) met ACR/EULAR criteria and 114 (39\%) also met AECG criteria; thus, 11 (4\%) patients fulfilled only ACR/EULAR, no patients AECG only, and $165(57 \%)$ patients neither criteria set. Concordance was excellent $(K=0.92)$. Compared to patients fulfilling both criteria sets, the 11 patients fulfilling only ACR/EULAR criteria had similar age and symptom duration but lower frequencies of xerophthalmia and xerostomia ( $p<0.01$ for each) and salivary gland dysfunction $(p<0.01)$; most had systemic involvement (91\%), including three (27\%) with no sicca symptoms; $91 \%$ had abnormal salivary gland biopsy and 46\% anti-Sjögren's-syndrome-related antigen A (anti-SSA); 64\% were diagnosed with pSS by the physician. SGUS was abnormal in 12\% of the 165 patients fulfilling no criteria set. Including SGUS among the ACR/EULAR criteria increased sensitivity from $87.4 \%$ to $91.1 \%$ when physician diagnosis was the reference standard.

Conclusions: Agreement between AECG and ACR/EULAR criteria sets is excellent. ACR/EULAR criteria are slightly more sensitive and classified some patients without sicca symptoms as having pSS. Including SGUS in the ACR/ EULAR criteria may further improve their sensitivity.

Keywords: Sjögren's syndrome, Primary, Classification criteria, Diagnosis, Ultrasonography

\footnotetext{
*Correspondence: divi.cornec@chu-brest.fr

${ }^{1}$ Centre National de Référence CERAINO, Service de Rhumatologie, Hôpital

de la Cavale Blanche, BP 824, F 29609 Brest cedex, France

${ }^{2}$ INSERM UMR1227, Lymphocytes B et Autoimmunité, Université de Bretagne

Occidentale, Brest, France

Full list of author information is available at the end of the article
} 


\section{Background}

Primary Sjögren's syndrome (pSS) is a chronic systemic auto-immune inflammatory disease characterised by secretory gland dysfunction leading to oral and/or ocular dryness in most patients. Furthermore, 30-50\% of patients with pSS exhibit a broad spectrum of systemic manifestations [1]. The prevalence in the general population is $0.02-0.1 \%$, and middle-aged women are predominantly affected [2-4]. Although mortality is not higher in patients with pSS than in the general population [5], the cardinal symptoms of ocular and oral dryness, fatigue, and diffuse pain severely diminish quality of life [6]. Despite recent insights into the pathophysiology of pSS [7], no treatment has been demonstrated to improve the course of the disease [8].

Over the last few decades, many classification systems have been developed to define pSS and assist in research and clinical practice. The set of subjective and objective criteria issued by the American-European Consensus Group (AECG) in 2002 has been the main classification system used in clinical studies during the last decade [9]. In 2012, the Sjögren's International Collaborative Clinical Alliance (SICCA) [10] issued new classification criteria, which were first endorsed by the American College of Rheumatology (ACR) [11]. Several studies then identified difficulties raised by the co-existence of the two criteria sets [12-14]. New consensual classification criteria for
pSS combining features of the earlier ACR and AECG criteria sets were therefore developed and validated jointly by ACR and EULAR committees [15, 16]. This ACR/ EULAR criteria set excludes the most common differential diagnoses. It also differs substantially from the earlier AECG criteria (Table 1) in that it considers systemic manifestations (defined as a EULAR Sjögren's Syndrome Disease Activity Index (ESSDAI) $\geq 1)[17,18]$, and sicca symptoms, as entry criteria. A weighted scoring system is then applied, with 3 points each for positive salivary gland biopsy (SGB) $[19,20]$ and positive anti-SSA antibodies and 1 point each for unstimulated whole salivary flow (UWSF) $\leq 0.1 \mathrm{~mL} / \mathrm{min}$ [21], Schirmer's test result $\leq$ $5 \mathrm{~mm} / 5 \mathrm{~min}$ and Ocular Staining Score (OSS) $\geq 5$ [22] or van Bijsterveld (VB) score $\geq 4$. A weighted score $\geq 4$ classifies the patient as having pSS.

Several recent studies assessed major salivary gland ultrasonography (SGUS) as a tool for diagnosing pSS [23-28]. Including SGUS in the AECG and ACR criteria sets may improve performance [23, 24]. However, SGUS is not among the ACR/EULAR criteria, because the procedure was not performed in the patients included in the cohorts used to develop and validate the criteria set.

The concordance and differences in the results of the AECG and ACR/EULAR criteria sets in independent patient populations must be evaluated to aid in interpreting comparisons of future clinical studies based on the new

Table 1 AECG versus ACR/EULAR criteria

\begin{tabular}{|c|c|c|c|}
\hline & \multirow[t]{2}{*}{2002 AECG criteria } & \multicolumn{2}{|l|}{2016 ACR/EULAR criteria } \\
\hline & & & Weight \\
\hline \multirow[t]{5}{*}{ Items } & \multirow{5}{*}{$\begin{array}{l}\text { 1. Ocular dryness symptoms } \\
\text { 2. Oral dryness symptoms } \\
\text { 3. Ocular signs: Schirmer's test } \leq 5 \mathrm{~mm} / 5 \mathrm{~min} \text { or } \\
\text { van Bijsterveld score } \geq 4 \\
\text { 4. Focus score } \geq 1 \text { foci } / 4 \mathrm{~mm}^{2} \text { on minor salivary } \\
\text { gland biopsy } \\
\text { 5. Salivary gland involvement: unstimulated } \\
\text { whole salivary flow } \leq 0.1 \mathrm{~mL} / \mathrm{min} \\
\text { 6. Positive anti-SSA or SSB antibodies }\end{array}$} & $\begin{array}{l}\text { 1. Labial salivary gland with focal lymphocytic } \\
\text { sialadenitis and focus score of } \geq 1 \text { foci/ } 4 \mathrm{~mm}^{2}\end{array}$ & 3 \\
\hline & & 2. Anti-SSA/Ro-positive & 3 \\
\hline & & $\begin{array}{l}\text { 3. Ocular Staining Score } \geq 5 \text { (or van Bijsterveld } \\
\text { score } \geq 4 \text { ) in at least one eye }\end{array}$ & 1 \\
\hline & & $\begin{array}{l}\text { 4. Schirmer's test } \leq 5 \mathrm{~mm} / 5 \mathrm{~min} \text { in at least one } \\
\text { eye }\end{array}$ & 1 \\
\hline & & $\begin{array}{l}\text { 5. Unstimulated whole saliva flow rate } \\
\leq 0.1 \mathrm{~mL} / \mathrm{min}\end{array}$ & 1 \\
\hline Rules for classification & $\begin{array}{l}\text { - Absence of exclusion } \text { criteria }^{a} \\
\text { - Presence of any } 4 \text { of the } 6 \text { items with at least } \\
\text { item } 4 \text { or } 6 \text {, or } \\
\text { - presence of any } 3 \text { of the } 4 \text { objective items } \\
\quad(3,4,5 \text {, and } 6)\end{array}$ & $\begin{array}{l}\text { Applies to any individual } \\
\text { - who meets the inclusion criteriab with at least } \\
\text { one symptom of ocular or oral dryness or } \\
\text { ESSDAI } \geq 1 \\
\text { - does not have any of the conditions listed as } \\
\text { exclusion criteriac } \\
\text { - and has a score of } \geq 4 \text { when the weights from } \\
\text { the } 5 \text { criteria items are summed }\end{array}$ & \\
\hline
\end{tabular}

\footnotetext{
AECG American-European Consensus Group, ACR American College of Rheumatology, SS Sjögren's syndrome, ESSDAl EULAR SS Disease Activity Index, anti-SSA anti-Sjögren's-syndrome-related antigen $A$

${ }^{a}$ Exclusion criteria in the AECG system: past head and neck radiation treatment, hepatitis C infection, acquired immunodeficiency syndrome (AIDS), pre-existing lymphoma, sarcoidosis, graft-versus-host disease, use of anticholinergic drugs (within a time shorter than fourfold the half-life of the drug)

${ }^{b}$ These criteria are applicable to any patient with at least one symptom of ocular or oral dryness or in whom there is a suspicion of Sjögren's syndrome (SS) based on the ESSDAI (at least one domain with a positive item).

${ }^{c}$ Exclusion criteria for ACR/EULAR criteria include a prior diagnosis of any of the following conditions, which would exclude diagnosis of SS and participation in SS studies or therapeutic trials because of overlapping clinical features or interference with criteria tests: history of head and neck radiation treatment, active hepatitis C infection (with confirmation by PCR), AIDS, sarcoidosis, amyloidosis, graft-versus-host disease, and lgG4-related disease
} 
criteria set to previously published studies. Here, our objectives were to assess agreement between the two criteria sets, to identify sources of disagreement, and to analyse SGUS findings according to patient classification.

\section{Methods}

\section{Inclusion and exclusion criteria}

We conducted a cross-sectional study in the singlecentre Brittany cohort of patients with suspected pSS (DIApSS cohort). Patients were included prospectively between January 2006 and September 2016 at the Brest University Hospital, Brest, France. As previously described $[23,29]$, patients were included if they had subjective ocular and/or oral dryness, major salivary gland swelling, extra-glandular manifestations consistent with pSS, or suggestive antibodies or other laboratory abnormalities. Patients were referred to our multidisciplinary clinics by their family physician, rheumatologist, internist, oral health specialist, or ophthalmologist. We excluded patients with a diagnosis of another connective tissue disease. All participants gave written informed consent, and the study was approved by the Brest University Hospital institutional review board.

\section{Standardised evaluation}

All patients underwent a comprehensive standardised clinical evaluation conducted by an experienced rheumatologist, an oral health specialist [30], and an ophthalmologist. UWSF $\leq 0.1 \mathrm{~mL} /$ minute [21], Schirmer's test result $\leq 5 \mathrm{~mm} / 5$ minutes, and $\mathrm{VB}$ score $\geq 4$ in at least one eye [31] were considered abnormal. All patients underwent standard laboratory tests, immunological tests (anti-nuclear antibodies, anti-SSA, anti-SSB, and rheumatoid factors, as previously described [32, 33]), and minor labial SGB. The rheumatologist determined the most probable diagnosis and assessed the clinical probability of pSS from 1 (definitely not pSS) to 4 (definitely pSS). All doubtful cases (two (probably not pSS) and 3 (probably pSS)) were reviewed by a panel of three experts (VD-P, AS, and SJJ) to reach a consensus. Bmode SGUS was performed by a single experienced operator (SJJ), who was blinded to the diagnosis and scored the echo-structure from 0 to 4 for each of the four major salivary glands (two parotid and two submandibular glands). The highest grade was recorded and was considered abnormal if $\geq 2$, as previously described [34].

\section{Statistical analysis}

Statistical tests were performed using the Statistical Package for the Social Sciences (SPSS 20.0; SPSS Inc., Chicago, IL, USA). Quantitative variables were described as mean \pm standard deviation and qualitative variables as number (percentage). Classification criteria were applied to each patient as described in Table 1 (only the VB score was used to apply ACR/EULAR criteria because the OSS was unavailable for most patients). Taking the physician's diagnosis as the reference standard for defining cases may lead to overestimation of the diagnostic performance of a classification system that has previously been used in everyday practice, with a risk of circular reasoning. Consequently, in our primary analysis, we compared patient groups defined by the two criteria sets. Agreement between classification criteria sets, and between classification criteria sets and physician diagnosis, was evaluated using Cohen's kappa coefficient ( $\mathrm{\kappa}$ ). To compare patient groups, we used the Mann-Whitney test, Fisher's exact test, or the chi-square test as appropriate. The characteristics of discordantly classified patients were detailed.

\section{Results}

\section{Cohort characteristics}

Between January 2006 and September 2016, 324 patients were included prospectively in the DIApSS cohort. Among them, 34 were excluded from the present study because they were diagnosed with, and met classification criteria for, another connective tissue disease (mainly rheumatoid arthritis and systemic lupus erythematosus). Thus, 290 patients were analysed in this study. Mean age was $55.8 \pm 13.4$ years, $92 \%(n=267)$ were female, mean symptom duration was $6.4 \pm 7.1$ years, and $47 \%$ (n $=135$ ) received a physician diagnosis of pSS.

\section{Comparison of ACR/EULAR and AECG criteria}

Table 2 compares patients meeting 2016 ACR/EULAR criteria and/or 2002 AECG criteria. More patients fulfilled ACR/EULAR criteria $(n=125,43.1 \%)$ than AECG criteria $(n=114,39.3 \%)$. All 114 patients meeting AECG criteria also met ACR/EULAR criteria (positive concordant group), whereas 11 (3.8\%) patients met only ACR/ EULAR criteria (discordant group). Finally, 165 (56.9\%) patients met neither criteria set (negative concordant group). Agreement between the criteria sets was excellent $(\kappa=0.92)$.

Compared to the 114 patients fulfilling both criteria sets, the 11 discordant patients fulfilling ACR/EULAR but not AECG criteria had similar mean age $(53.6 \pm 16.2$ versus $56.6 \pm 13.7$ years, $p=0.56)$ and mean symptom duration $(5.5 \pm 6.7$ versus $6.6 \pm 7.1$ years, $p=0.46)$. The discordant group had lower prevalence of sicca symptoms (ocular dryness, $18.2 \%$ versus $96.5 \%, p<0.01$; and oral dryness, $54.5 \%$ versus $97.4 \%, p<0.01$ ) and salivary gland dysfunction (UWSF $\leq 0.1 \mathrm{~mL} / \mathrm{min}$ : $18 \%$ versus $70.9 \%, p<0.01)$. Of the 11 discordant patients, 10 (90.9\%) had systemic involvement (ESSDAI $\geq 1$ ); mean ESSDAI was similar in the discordant and positive concordant groups $(4.6 \pm 3.2$ versus $4.8 \pm 5.5, p=0.58)$. Compared to the positive concordant group, a larger 
Table 2 Comparison of patients meeting 2016 ACR/EULAR criteria and/or 2002 AECG criteria

\begin{tabular}{|c|c|c|c|c|}
\hline & $\begin{array}{l}\text { Patients fulfilling both } \\
\text { sets of criteria } \\
n=114\end{array}$ & $\begin{array}{l}\text { Patients fulfilling ACR/EULAR } \\
\text { set of criteria only } \\
n=11\end{array}$ & $\begin{array}{l}\text { Patients fulfilling neither } \\
\text { set of criteria } \\
n=165\end{array}$ & $p$ value* \\
\hline Age (years, mean $\pm S D$ ) & $56.6 \pm 13.7$ & $53.6 \pm 16.2$ & $55.0 \pm 12.6$ & 0.56 \\
\hline Symptom duration (years, mean \pm SD) & $6.6 \pm 7.1$ & $5.5 \pm 6.7$ & $5.6 \pm 6.2$ & 0.46 \\
\hline Female, $n(\%)$ & $106(93)$ & $11(100)$ & $150(91)$ & 1 \\
\hline Xerophthalmia ${ }^{a}, n(\%)$ & $110(97)$ & $2(18)$ & $141(86)$ & $<0.01$ \\
\hline Xerostomia ${ }^{a}, n(\%)$ & $111(97)$ & $6(55)$ & $144(87)$ & $<0.01$ \\
\hline ESSDAI (mean \pm SD) & $4.8 \pm 5.5$ & $4.6 \pm 3.2$ & 3. $8 \pm 4.8$ & 0.58 \\
\hline $\mathrm{ESSDAI} \geq 1, n(\%)$ & $98(86)$ & $10(91)$ & $115(70)$ & 1.00 \\
\hline Only sicca, $n(\%)$ & $16(14)$ & $1(9)$ & $52(32)$ & 1.00 \\
\hline Only ESSDAI, $n(\%)$ & $1(1)$ & $3(27)$ & $6(4)$ & $<0.01$ \\
\hline Schirmer's test $\leq 5 \mathrm{~mm} / 5 \mathrm{~min}, n(\%)$ & $70 / 110(64)$ & $4(36)$ & 47/154 (31) & 0.18 \\
\hline$V B \geq 4, n(\%)$ & $24 / 80(30)$ & $2 / 4(50)$ & $12 / 85(14)$ & 0.58 \\
\hline UWSF $\leq 0.1 \mathrm{~mL} / \mathrm{min}, n(\%)$ & 73/103 (71) & $2(18)$ & $56 / 152(37)$ & $<0.01$ \\
\hline Abnormal SGB, $n(\%)$ & 93/112 (83) & $10(91)$ & 22/159 (14) & 0.69 \\
\hline Anti-SSA and/or SSB positivity, $n$ (\%) & $77(68)$ & $5(46)$ & $6(4)$ & 0.14 \\
\hline Anti-SSA, $n(\%)$ & $75(66)$ & $5(46)$ & $5(3)$ & 0.18 \\
\hline ANA $\geq 1: 320, n(\%)$ & $83(73)$ & $8(73)$ & $55(33)$ & 1.00 \\
\hline RF positivity, $n(\%)$ & $51 / 112(46)$ & $4(36)$ & 18/165 (11) & 0.75 \\
\hline $\operatorname{lgG}(\mathrm{g} / \mathrm{L}$, mean $\pm \mathrm{SD})$ & $14.5 \pm 7.9$ & $14.7 \pm 5.1$ & $10.5 \pm 3.5$ & 0.49 \\
\hline SGUS score $\geq 2, n(\%)$ & $61 / 105(58)$ & $4 / 9(44)$ & $17 / 141(12)$ & 0.50 \\
\hline Physician diagnosis of pSS, $n$ (\%) & $111(97)$ & $7(64)$ & $17(10)$ & $<0.01$ \\
\hline
\end{tabular}

ACR American College of Rheumatology, AECG American-European Consensus Group, ESSDAI EULAR SS Disease Activity Index, Anti-SSA anti-Sjögren's-syndromerelated antigen $A, V B$ van Bijsterveld score, UWSF unstimulated whole salivary flow, SGB salivary gland biopsy, $A N A$ antinuclear antibodies, $R F$ rheumatoid factor, SGUS salivary gland ultrasonography, pSS, primary Sjögren's syndrome

*Comparison of patients fulfilling both criteria sets and of patients fulfilling only the ACR/EULAR criteria set

${ }^{\text {a }}$ Subjective complaints by the patients

proportion of patients in the discordant group had ESSDAI $\geq 1$ but no sicca symptoms $(27.3 \%$ versus $0.9 \%, p<$ $0.01)$. In the discordant group, $10 / 11$ (90.9\%) patients had a positive SGB and 5/11 (45.4\%) had anti-SSA and/ or anti-SSB antibodies. In the overall cohort, two patients had anti-SSB but not anti-SSA antibodies, and therefore met the serological criterion in the AECG set but not the ACR/EULAR set. These two patients had typical features of pSS and fulfilled both AECG and ACR/EULAR criteria based on abnormal SGB and UWSF findings.

In patients meeting ACR/EULAR criteria, the main reasons for not also meeting AECG criteria were absence of sicca symptoms, presence of either xerophthalmia or xerostomia but not both, and presence of only two other criteria including anti-SSA or positive SGB. Of note, the VB score was available for only 4/11 discordant patients; among the remaining 7 patients, 4 had a negative Schirmer's test: these 4 patients may have also fulfilled AECG criteria had a VB score been obtained and had it been positive (which was the case in only $30 \%$ of patients fulfilling AECG criteria, Table 2).
The physician diagnosed pSS in 7/11 (63.6\%) discordant patients compared to $111 / 114$ (97.4\%) positive concordant patients $(p<0.01)$. When the physician's diagnosis was used as the reference standard, the ACR/ EULAR criteria had $87.4 \%$ sensitivity and $95.4 \%$ specificity for pSS, compared to $82.2 \%$ and $98.1 \%$, respectively, for the AECG criteria. Concordance with the physician diagnosis was similar for the AECG and ACR/EULAR criteria ( $\mathrm{K}=0.81$ and $\mathrm{\kappa}=0.83$, respectively).

\section{Detailed features of patients fulfilling only ACR/EULAR criteria $(n=11)$}

Table 3 details the features of the 11 patients fulfilling only ACR/EULAR criteria. All were female. Among them, 10 had systemic activity (ESSDAI $\geq 1$ ): 7 had inflammatory arthralgia, 2 cytopenia, 1 parotidomegaly, 1 lymphadenopathy, 1 peripheral axonal neuropathy, and 5 positive items in the biological ESSDAI domain (3 with moderate and 2 with low activity, and all 5 with involvement of other domains). Five patients had other organspecific auto-immune diseases such as thyroiditis and hepatitis. In the four patients who did not receive a 
Le Goff et al. Arthritis Research \& Therapy (2017) 19:269

Page 5 of 10

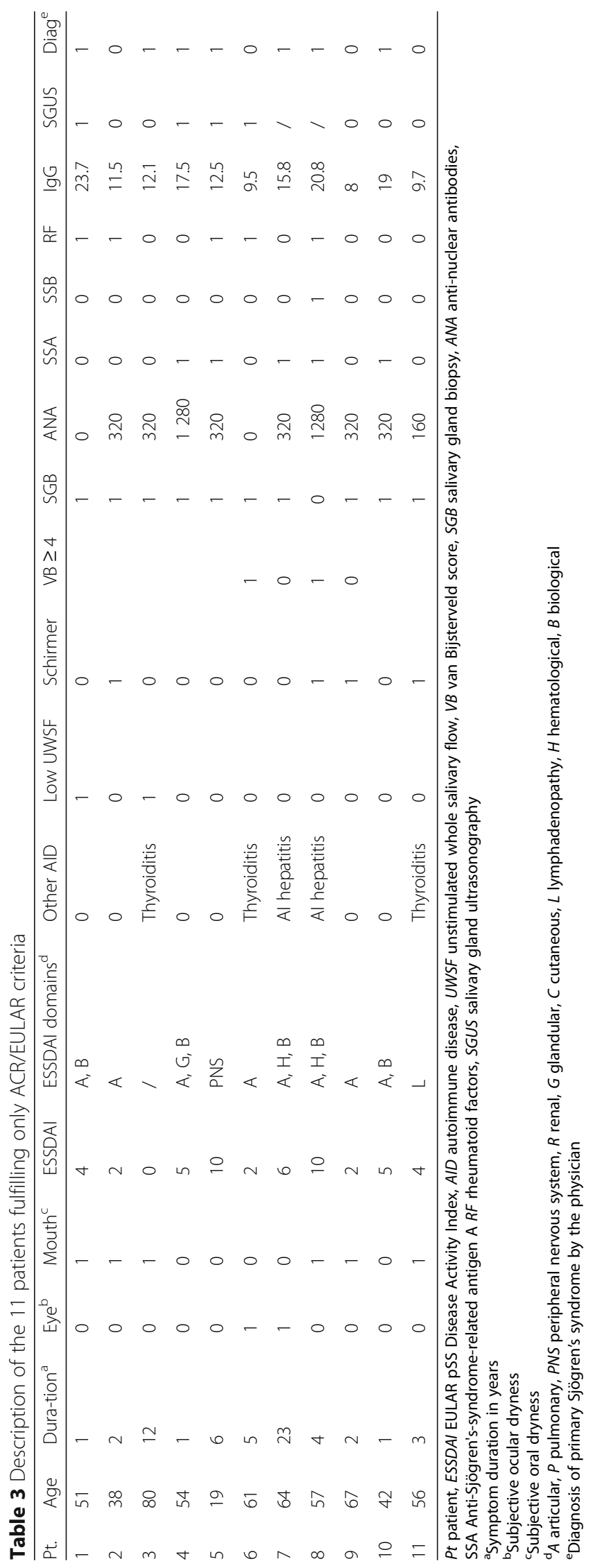


physician diagnosis of pSS, the physician felt that the most likely diagnosis was idiopathic sicca syndrome $(n=3)$ or undifferentiated inflammatory arthritis $(n=1)$.

\section{Detailed features of patients who had physician- diagnosed pSS but met neither of the criteria sets} Table 4 details the features of the 17 patients (16 females) who met neither of the criteria sets but received a diagnosis of pSS from the physician. All but one had sicca symptoms, 10 had recent-onset disease (defined as symptom duration $\leq 5$ years), 12 had systemic involvement with no other explanation than pSS, 9 had an abnormal SGB, and 4 had anti-SSA/SSB antibodies. The main reason for not meeting criteria was absence of objective signs of ocular or oral dryness (only one patient had a positive Schirmer's test and another an abnormal VB score). Four patients had a negative SGB and no anti-SSA; all four had sicca symptoms, typical systemic involvement (with no differential diagnosis), and a biological sign not included in the criteria set (high serum IgG levels, rheumatoid factors, or hightitre anti-nuclear antibodies).

\section{Impact of salivary-gland ultrasonography (SGUS) on classification}

Among the 290 patients in the cohort, 255 underwent SGUS, which was abnormal in 82 patients $(31.2 \%)$. The proportion of patients with abnormal SGUS was $44.4 \%$ in the discordant group and $58.1 \%$ in the positive concordant group $(p=0.50)$. Among the 17 patients who met neither criteria set but received a physician diagnosis of pSS, 7 (41\%) had SGUS abnormalities. These seven patients had either anti-SSA antibodies or abnormal SGB but did not fulfil the criteria set because of normal findings in Schirmer's test, the VB score, and UWSF. This suggests that including SGUS in the ACR/EULAR criteria as an alternative procedure for objectively assessing exocrine gland involvement may further improve sensitivity. Only $8 \%$ of patients who did not receive a physician diagnosis of pSS had an abnormal SGUS, confirming the good specificity of the procedure. We tested the possibility of including SGUS among ACR/EULAR criteria, arbitrarily giving SGUS the same weight as UWSF, Schirmer's test, and the VB score (1 point if positive) and using the same cutoff $(\geq 4)$ to classify a patient as having pSS. Using a physician diagnosis of pSS as the reference standard, including SGUS inclusion among ACR/EULAR criteria slightly increased their sensitivity from $87.4 \%$ to $91.1 \%$ (absolute increase $3.7 \%$ ), while the specificity remained over $90 \%$ (95.4\% without and $93.8 \%$ with SGUS). Importantly, no patient fulfilled these modified criteria without positive SGB or anti-SSA.

\section{Discussion}

In a prospective cohort of consecutive patients from everyday clinical practice, with sicca symptoms or systemic involvement suggesting pSS, agreement between AECG and ACR/EULAR criteria was excellent $(\kappa=0.92)$. Thus, these two criteria sets would select similar patient populations for future trials and clinical studies. This excellent agreement is unsurprising because, despite conceptual differences, the two sets share many items. Nonetheless, ACR/EULAR criteria were slightly more sensitive, allowing some patients with systemic disease but mild or no sicca symptoms to be classified as having pSS. SGUS was positive in a notable proportion of the patients who received a physician diagnosis of pSS but did not fulfil either criteria set. Thus, including SGUS in the ACR/ EULAR criteria may further improve sensitivity.

With the ACR/EULAR criteria, some patients without sicca symptoms may be classified as having pSS if they have systemic features defined by the ESSDAI domains. This point was not specifically addressed during criteria development, because presence of sicca manifestations was required for inclusion in the three different cohorts used to create the criteria [16]. Only three patients in our study met ACR/EULAR criteria despite having no sicca manifestations. These three patients had anti-SSA antibodies and abnormal SGB and received a physician diagnosis of pSS. They had recent-onset disease (with two patients having symptom duration of only 1 year). Although UWSF and Schirmer's test were normal in these three patients, consistent with the absence of subjective sicca, two patients had abnormal SGUS, suggesting that a pathologic process was developing in their major salivary glands, possibly heralding the subsequent development of sicca manifestations. Prospective longitudinal studies with long follow up will be necessary to assess this hypothesis. Of note, no patient scored positive in the biological ESSDAI domain without having clinical systemic manifestations or sicca symptoms. Among patients who received a physician diagnosis of pSS but did not meet classification criteria, only one had systemic involvement without sicca symptoms. Thus, adding systemic involvement to the criteria, as proposed recently [35], would probably not significantly affect performance of the criteria set in clinical practice [36].

Exclusion of anti-SSB positivity from the ACR/EULAR criteria was based on the finding that anti-SSB-positive/ anti-SSA-negative patients in the SICCA cohort lacked key phenotypic features of pSS [37]. In our cohort, only two patients had this serologic profile and both exhibited typical features of pSS and fulfilled ACR/EULAR criteria based on abnormal SGB and objective ocular and oral dryness. In the 2012 ACR classification criteria [11], the combination of positive rheumatoid factor and high-titre anti-nuclear antibodies was proposed as an alternative 


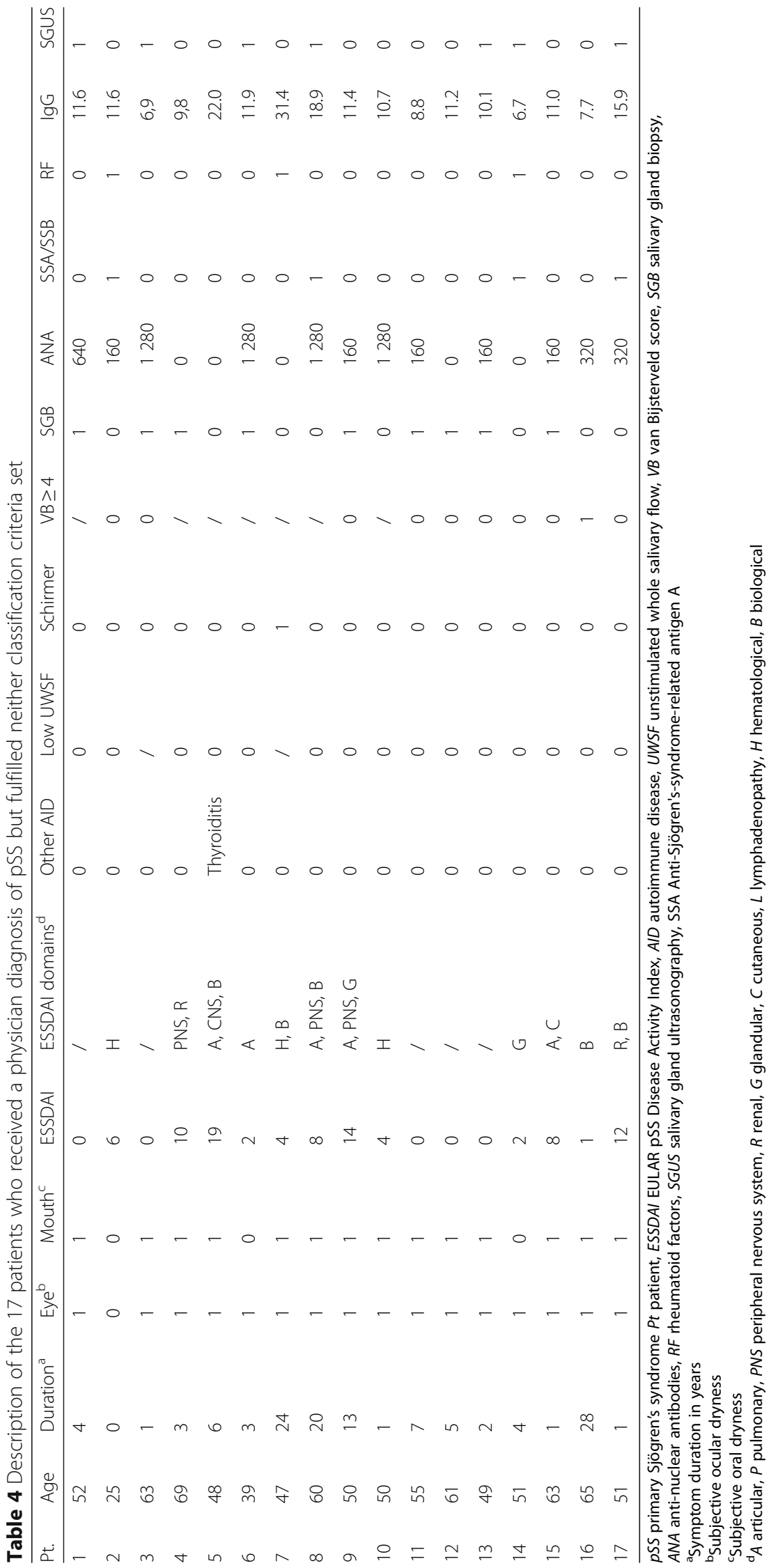


serologic item for anti-SSA-negative patients but was not selected during the development of the ACR/ EULAR criteria. We previously reported that in our cohort, despite an association with pSS diagnosis, this alternative serologic item did not improve classification criteria performance [32].

The AECG criteria include sialography and salivary scintigraphy as objective methods for assessing salivary gland involvement. Neither test was included in the ACR/EULAR criteria. These tests are considered obsolete and are not usually performed in pSS referral centres. Neither test was used in our cohort, and salivary gland dysfunction was defined based only on the UWSF, which is among the ACR/EULAR criteria. However, SGUS is a simple and non-invasive procedure that is readily available to many rheumatologists and supplies important information on the structural changes that develop in the major salivary glands in pSS. Several recent studies found that SGUS exhibited good metrologic properties [28]. In particular, many patients with recent disease already show typical SGUS features, which usually remain stable over the first few years following the diagnosis [38]. Furthermore, SGUS may also be useful as a follow-up tool, as it may help to predict the response to therapy [39] and to detect improvements after active treatment [40]. An international panel of experts was recently established to measure the reproducibility of SGUS and to formally assess the appropriateness of including SGUS among future classification criteria for pSS [41, 42]. Our present analysis suggests that, in addition to UWSF, Schirmer's test, and the VB score, SGUS may deserve consideration as an alternative objective test for assessing exocrine gland involvement, thereby further increasing sensitivity. Despite lower sensitivity compared to SGB, SGUS brings independent diagnostic data: as we and others previously concluded [23, 43-45], SGUS is not supposed to replace SGB, but could be used as a first step before SGB in the diagnostic algorithm for pSS, and the biopsy could be avoided in anti-SSA+ patients with a positive SGUS.

A recent study from Japan compared the ACR/EULAR criteria, AECG criteria, and Japanese criteria in a multicentre retrospective cohort of 499 patients with suspected pSS [46]. Agreement was poor. With the physician diagnosis as the reference standard, ACR/EULAR criteria were more sensitive than AECG criteria (95.4\% versus $89.4 \%$, respectively) but considerably less specific (72.1\% versus $84.3 \%$, respectively). While these sensitivity rates are consistent with ours $(87.4 \%$ and $82.2 \%$ for ACR/EULAR and AECG, respectively), both criteria sets had far lower specificity in the Japanese study than in ours $(72.1 \%$ versus $95.4 \%$ and $89.4 \%$ versus $98.1 \%$ for ACR/EULAR and AECG, respectively). These findings may indicate important differences in the way physicians diagnose pSS in clinical practice in Japan and in Europe, with Japanese physicians generally identifying pSS cases in clinical practice using Japanese criteria for this disease, which were originally developed as a diagnostic tool [47]. Furthermore, all doubtful cases in our study were reviewed by a panel of three experts to reach a consensus, whereas in the Japanese study [46] the diagnoses were made by the physicians in charge (from ten different hospitals), leaving room for greater variability in the reference standard used to define pSS. Another important point is that stimulated salivary flow (measured by the Saxon test or the gum test) was substituted for UWSF in some patients in the Japanese [46] study, although their diagnostic value is lower than that of UWSF [21].

A limitation of our study is that ocular surface staining (VB score) was performed in only 169 patients (58\%). This fact reflects the use of the different diagnostic tests in everyday clinical practice at our centre. However, the VB score was $\geq 4$ in only $22.5 \%$ of the patients who had this test, including $12(14.0 \%)$ of the 85 patients who met neither criteria set. The vast majority of patients meeting neither criteria set had negative SGB findings and no anti-SSA antibodies and, therefore, would not have fulfilled the criteria even if they had an abnormal VB score. Among the 17 patients who received a physician diagnosis of pSS but fulfilled neither criteria set, only 4 would have fulfilled the ACR/EULAR criteria if they had had a VB available and if this had been positive. It is therefore unlikely that this limitation substantially affected our results.

\section{Conclusions}

In conclusion, in a large cohort of patients with suspected pSS, agreement between the newly developed ACR/EULAR criteria and the earlier AECG criteria was excellent. However, ACR/EULAR criteria were slightly more sensitive and allowed some patients with early disease and prominent systemic features to be classified as having pSS. Our findings also confirm the good metrologic properties of SGUS, suggesting that adding SGUS to classification criteria, as discussed in the report describing the ACR/EULAR criteria $[15,16]$, may improve classification performance.

\footnotetext{
Abbreviations

ACR: American College of Rheumatology; AECG: American-European Consensus Group; Anti-SSA: Anti-Sjögren's-syndrome-related antigen A; ESSDAI: European League Against Rheumatism Sjögren's Syndrome Disease Activity Index; EULAR: European League Against Rheumatism; OSS: Ocular Staining Score; pSS: Primary Sjögren's syndrome; SGB: Salivary gland biopsy; SGUS: Salivary-gland ultrasonography; SICCA: Sjögren's International Collaborative Clinical Alliance; UWSF: Unstimulated whole salivary flow; VB: van Bijsterveld
} 


\section{Funding}

No funding was received for this study.

\section{Availability of data and materials}

All relevant generated data and material are included in the manuscript.

\section{Authors' contributions}

DC, AS, and VDP designed the study. MLG and DC analysed the data and drafted the manuscript. All the authors participated in data collection, manuscript revision, and final manuscript approval for submission.

\section{Ethics approval and consent to participate}

All participants gave written informed consent, and the study was approved by the Brest University Hospital institutional review board.

\section{Consent for publication}

No personal and identifiable data are included in the manuscript.

\section{Competing interests}

The authors have no conflicts of interest to declare concerning this work.

\section{Publisher's Note}

Springer Nature remains neutral with regard to jurisdictional claims in published maps and institutional affiliations.

\section{Author details}

${ }^{1}$ Centre National de Référence CERAINO, Service de Rhumatologie, Hôpital de la Cavale Blanche, BP 824, F 29609 Brest cedex, France. ${ }^{2}$ INSERM UMR1227, Lymphocytes B et Autoimmunité, Université de Bretagne Occidentale, Brest, France. ${ }^{3}$ Anatomie et Pathologie, CHRU Brest, Brest, France. ${ }^{4}$ Médecine Interne, CHRU Brest, Brest, France. ${ }^{5}$ Explorations Fonctionnelles Neurologiques, CHRU Brest, Brest, France. ${ }^{6}$ Ophtalmologie, CHRU Brest, Brest, France. ${ }^{7}$ Odontologie, CHRU Brest, Brest, France. ${ }^{8}$ Laboratoire d'Immunologie et Immunothérapie, CHRU Brest, Brest, France.

Received: 20 July 2017 Accepted: 16 November 2017

\section{Published online: 06 December 2017}

\section{References}

1. Brito-Zerón P, Baldini C, Bootsma H, Bowman SJ, Jonsson R, Mariette $X$, et al. Sjögren syndrome. Nat Rev Dis Primer. 2016;2:16047.

2. Cornec D, Chiche L. Is primary Sjögren's syndrome an orphan disease? A critical appraisal of prevalence studies in Europe. Ann Rheum Dis. 2015;74:e25.

3. Maciel G, Crowson CS, Matteson EL, Cornec D. Prevalence of primary Sjögren's syndrome in a population-based cohort in the United States. Arthritis Care Res (Hoboken). 2017;69(10):1612-1616.

4. Brito-Zerón P, Acar-Denizli N, Zeher M, Rasmussen A, Seror R, Theander E, et al. Influence of geolocation and ethnicity on the phenotypic expression of primary Sjögren's syndrome at diagnosis in 8310 patients: a crosssectional study from the Big Data Sjögren Project Consortium. Ann Rheum Dis. 2017;76:1042-50

5. Maciel G, Crowson CS, Matteson EL, Cornec D. Incidence and mortality of physician-diagnosed primary Sjögren syndrome: time trends over a 40-year period in a population-based US cohort. Mayo Clin Proc. 2017:92(5):734-43.

6. Cornec D, Devauchelle-Pensec V, Mariette X, Jousse-Joulin S, Berthelot J-M, Perdriger A, et al. Severe health-related quality-of-life impairment in active primary Sjögren's syndrome is driven by patient-reported outcomes: data from a large therapeutic trial. Arthritis Care Res (Hoboken). 2017:69(4):528-535.

7. Nocturne G, Mariette X. Advances in understanding the pathogenesis of primary Sjögren's syndrome. Nat Rev Rheumatol. 2013;9:544-56.

8. Saraux A, Pers J-O, Devauchelle-Pensec V. Treatment of primary Sjögren syndrome. Nat Rev Rheumatol. 2016;12:456-71.

9. Vitali C, Bombardieri S, Jonsson R, Moutsopoulos HM, Alexander EL, Carsons SE, et al. Classification criteria for Sjögren's syndrome: a revised version of the European criteria proposed by the American-European Consensus Group. Ann Rheum Dis. 2002;61:554-8.

10. Daniels TE, Cox D, Shiboski CH, Schiødt M, Wu A, Lanfranchi $H$, et al. Associations between salivary gland histopathologic diagnoses and phenotypic features of Sjögren's syndrome (SS) among 1726 registry participants. Arthritis Rheum. 2011;63:2021-30
11. Shiboski SC, Shiboski CH, Criswell LA, Baer AN, Challacombe S, Lanfranchi H, et al. American College of Rheumatology classification criteria for Sjögren's syndrome: A data-driven, expert consensus approach in the Sjögren's International Collaborative Clinical Alliance Cohort. Arthritis Care Res. 2012;64:475-87.

12. Vitali C, Bootsma H, Bowman SJ, Dorner T, Gottenberg J-E, Mariette X, et al. Classification criteria for Sjogren's syndrome: we actually need to definitively resolve the long debate on the issue. Ann Rheum Dis. 2013;72:476-8.

13. Cornec D, Saraux A, Cochener B, Pers J-O, Jousse-Joulin S, Renaudineau Y, et al. Level of agreement between 2002 American-European Consensus Group and 2012 American College of Rheumatology classification criteria for Sjögren's syndrome and reasons for discrepancies. Arthritis Res Ther. 2014;16:R74

14. Rasmussen A, Ice JA, Li H, Grundahl K, Kelly JA, Radfar L, et al. Comparison of the American-European Consensus Group Sjögren's syndrome classification criteria to newly proposed American College of Rheumatology criteria in a large, carefully characterised sicca cohort. Ann Rheum Dis. 2014;73:31-8.

15. Shiboski CH, Shiboski SC, Seror R, Criswell LA, Labetoulle M, Lietman TM, et al. 2016 American College of Rheumatology/European League Against Rheumatism classification criteria for primary Sjögren's syndrome: a consensus and data-driven methodology involving three international patient cohorts. Arthritis Rheumatol. 2017;69:35-45

16. Shiboski CH, Shiboski SC, Seror R, Criswell LA, Labetoulle M, Lietman TM, et al. 2016 American College of Rheumatology/European League Against Rheumatism classification criteria for primary Sjögren's syndrome: a consensus and data-driven methodology involving three international patient cohorts. Ann Rheum Dis. 2017;76:9-16.

17. Seror R, Theander E, Brun JG, Ramos-Casals M, Valim V, Dörner T, et al. Validation of EULAR primary Sjögren's syndrome disease activity (ESSDAI) and patient indexes (ESSPRI). Ann Rheum Dis. 2015;74:859-66.

18. Seror R, Ravaud P, Bowman SJ, Baron G, Tzioufas A, Theander E, et al. EULAR Sjogren's syndrome disease activity index: development of a consensus systemic disease activity index for primary Sjogren's syndrome. Ann Rheum Dis. 2010;69:1103-9.

19. Fisher BA, Brown RM, Bowman SJ, Barone F. A review of salivary gland histopathology in primary Sjögren's syndrome with a focus on its potential as a clinical trials biomarker. Ann Rheum Dis. 2015;74(9):1645-50.

20. Fisher BA, Jonsson R, Daniels T, Bombardieri M, Brown RM, Morgan $P$, et al. Standardisation of labial salivary gland histopathology in clinical trials in primary Sjögren's syndrome. Ann Rheum Dis. 2017;76(7):1161-1168.

21. Navazesh M, Kumar SKS, University of Southern California School of Dentistry. Measuring salivary flow: challenges and opportunities. J Am Dent Assoc. 2008:139(Suppl):35S-40S.

22. Whitcher JP, Shiboski CH, Shiboski SC, Heidenreich AM, Kitagawa K, Zhang $\mathrm{S}$, et al. A simplified quantitative method for assessing keratoconjunctivitis sicca from the Sjögren's Syndrome International Registry. Am J Ophthalmol. 2010:149:405-15.

23. Cornec D, Jousse-Joulin S, Pers J-O, Marhadour T, Cochener B, BoisraméGastrin $S$, et al. Contribution of salivary gland ultrasonography to the diagnosis of Sjögren's syndrome: toward new diagnostic criteria? Arthritis Rheum. 2013:65:216-25.

24. Cornec D, Jousse-Joulin S, Marhadour T, Pers J-O, Boisramé-Gastrin S, Renaudineau Y, et al. Salivary gland ultrasonography improves the diagnostic performance of the 2012 American College of Rheumatology classification criteria for Sjögren's syndrome. Rheumatol Oxf Engl. 2014;53:1604-7.

25. Baldini C, Luciano N, Tarantini G, Pascale R, Sernissi F, Mosca M, et al. Salivary gland ultrasonography: a highly specific tool for the early diagnosis of primary Sjögren's syndrome. Arthritis Res Ther. 2015;17:146.

26. Luciano N, Baldini C, Tarantini G, Ferro F, Sernissi F, Varanini V, et al. Ultrasonography of major salivary glands: a highly specific tool for distinguishing primary Sjögren's syndrome from undifferentiated connective tissue diseases. Rheumatol Oxf Engl. 2015;54:2198-204.

27. Hammenfors DS, Brun JG, Jonsson R, Jonsson MV. Diagnostic utility of major salivary gland ultrasonography in primary Sjögren's syndrome. Clin Exp Rheumatol. 2015;33:56-62.

28. Jousse-Joulin S, Milic V, Jonsson MV, Plagou A, Theander E, Luciano N, et al. Is salivary gland ultrasonography a useful tool in Sjögren's syndrome? A systematic review. Rheumatol Oxf Engl. 2016;55:789-800.

29. Cornec D, Saraux A, Jousse-Joulin S, Pers J-O, Boisramé-Gastrin S, Renaudineau $Y$, et al. The differential diagnosis of dry eyes, dry mouth, and parotidomegaly: a comprehensive review. Clin Rev Allergy Immunol. 2015;49:278-87. 
30. Le Gall M, Cornec D, Pers J-O, Saraux A, Jousse-Joulin S, Cochener B, et al. A prospective evaluation of dental and periodontal status in patients with suspected Sjögren's syndrome. Jt Bone Spine Rev Rhum. 2016;83:235-6.

31. van Bijsterveld OP. Diagnostic tests in the Sicca syndrome. Arch Ophthalmol. 1969;82:10-4.

32. Cornec D, Saraux A, Pers J-O, Jousse-Joulin S, Marhadour T, Roguedas-Contios A$M$, et al. Diagnostic accuracy of blood B-cell subset profiling and autoimmunity markers in Sjögren's syndrome. Arthritis Res Ther. 2014;16:R15.

33. Capaldo C, Carvajal Alegria G, Cornec D, Jousse-Joulin S, Devauchelle-Pensec V, Renaudineau $Y$. The active immunological profile in patients with primary Sjögren's syndrome is restricted to typically encountered autoantibodies. Clin Exp Rheumatol. 2016;34:722.

34. Cornec D, Devauchelle-Pensec V, Saraux A, Jousse-Joulin S. [Clinical usefulness of salivary gland ultrasonography in Sjögren's syndrome: where are we now?]. Rev Med Interne. 2016;37:186-94. Fondée Par Société Natl Francaise Médecine Interne.

35. Tezcan ME, Kucuk H, Goker B. ACR/EULAR Sjögren classification criteria may not be adequate for extraglandular disease and necessitates defining "seronegative Sjögren's syndrome." Arthritis Rheumatol. 2017;69(6):1341-1342

36. Vitali C, Scofield $H$, Shiboski SC, Seror $R$, Criswell LA, Labetoulle M, et al. Authors' response to Tezcan and Colleagues' letter to the editor. Arthritis Rheumatol. 2017:69(6):1342.

37. Baer AN, McAdams DeMarco M, Shiboski SC, Lam MY, Challacombe S, Daniels TE, et al. The SSB-positive/SSA-negative antibody profile is not associated with key phenotypic features of Sjögren's syndrome. Ann Rheum Dis. 2015:74:1557-61

38. Gazeau P, Cornec D, Jousse-Joulin S, Guellec D, Saraux A, DevauchellePensec $\mathrm{V}$. Time-course of ultrasound abnormalities of major salivary glands in suspected Sjögren's syndrome. Joint Bone Spine. 2017. doi:10.1016/j. jbspin.2017.02.007. [Epub ahead of print].

39. Cornec D, Jousse-Joulin S, Costa S, Marhadour T, Marcorelles P, Berthelot J$M$, et al. High-grade salivary-gland involvement, assessed by histology or ultrasonography, is associated with a poor response to a single rituximab course in primary Sjögren's syndrome: data from the TEARS randomized trial. PLoS One. 2016;11:e0162787.

40. Jousse-Joulin S, Devauchelle-Pensec V, Cornec D, Marhadour T, Bressollette L, Gestin S, et al. Brief Report: Ultrasonographic assessment of salivary gland response to rituximab in primary Sjögren's syndrome. Arthritis Rheumatol. 2015;67:1623-8.

41. Jousse-Joulin S, Nowak E, Cornec D, Brown J, Carr A, Carotti M, et al. Salivary gland ultrasound abnormalities in primary Sjögren's syndrome: consensual US-SG core items definition and reliability. RMD Open. 2017;3:e000364.

42. Delli K, Arends S, van Nimwegen JF, Dijkstra PU, Stel AJ, Spijkervet FKL, et al. Ultrasound of the major salivary glands is a reliable imaging technique in patients with clinically suspected primary Sjögren's syndrome. Ultraschall Med. 2017. doi:10.1055/s-0043-104631. [Epub ahead of print]

43. Mossel E, Delli K, van Nimwegen JF, Stel AJ, Kroese FGM, Spijkervet FKL, et al. Ultrasonography of major salivary glands compared with parotid and labial gland biopsy and classification criteria in patients with clinically suspected primary Sjögren's syndrome. Ann Rheum Dis. 2017;76(11):1883-9.

44. Carvajal Alegria G, Costa S, Jousse-Joulin S, Marcorelles P, Pers J-O, Saraux A et al. What is the agreement between pathological features of parotid gland and labial salivary gland biopsies? Ann Rheum Dis. 2017. doi:10.1136/ annrheumdis-2017-212289. [Epub ahead of print].

45. Mossel E, Delli K, van Nimwegen JF, Stel AJ, Haacke EA, Kroese FGM, et al. The parotid gland connection: ultrasound and biopsies in primary Sjögren's syndrome. Ann Rheum Dis. 2017. doi:10.1136/annrheumdis-2017-212331. [Epub ahead of print].

46. Tsuboi H, Hagiwara S, Asashima H, Takahashi H, Hirota T, Noma H, et al. Comparison of performance of the 2016 ACR-EULAR classification criteria for primary Sjögren's syndrome with other sets of criteria in Japanese patients. Ann Rheum Dis. 2017;76(12):1980-5.

47. Fujibayashi T, Sugai S, Miyasaka N, Hayashi Y, Tsubota K. Revised Japanese criteria for Sjögren's syndrome (1999): availability and validity. Mod Rheumatol. 2004;14:425-34.

\section{Submit your next manuscript to BioMed Central and we will help you at every step:}

- We accept pre-submission inquiries

- Our selector tool helps you to find the most relevant journal

- We provide round the clock customer support

- Convenient online submission

- Thorough peer review

- Inclusion in PubMed and all major indexing services

- Maximum visibility for your research

Submit your manuscript at www.biomedcentral.com/submit
Biomed Central 